\title{
SOLEDAD, ESCRITURA Y CELEBRACIÓN DE LA FINITUD EN LOS ENSAYOS DE MICHELDE MONTAIGNE
}

\author{
LONELINESS, WRITING AND CELEBRATION OF THE FINITE \\ CONDITION INTO THE ESSAYS OF MICHEL DE MONTAIGNE
}

\author{
Víctor H. Palacios Cruz ${ }^{1}$ \\ Universidad Católica Santo Toribio de Mogrovejo (Perú)
}

Recibido: 11-01-2013

Aceptado: 28-01-2013

Resumen: Montaigne traza una conciencia de la individualidad en un punto medio que evita tanto la deploración del yo del luteranismo como la absolutización de la razón del cartesianismo. Somos un punto en el tiempo y el espacio, pequeñez que desestima cualquier divinización del juicio personal y, de paso, explica la pluralidad del mundo. Pequeñez que alienta tanto el trato con la interioridad como el interés por los otros.

Palabras-clave: Montaigne; filosofía moderna; subjetividad, hermenéutica, introspección, escritura.

\begin{abstract}
Montaigne fosters a sort of awareness of the individuality, which is halfway in between the Lutheran denial of the self and the Cartesian absolutization of reason. We are just a tiny dot in time and space; a fact that prevents us from deifying our personal judgment and, in so doing, explains the plurality of the world. And this smallness encourages us both to care of our own intimacy, and to worry about the others.
\end{abstract}

Key-words: Montaigne, Modern Philosophy, Subjectivity, Hermeneutics, Introspection, Writing.

[1] (vpalacios@usat.edu.pe) Nacido en Piura (Perú). Diplomado, Maestría y estudios de doctorado en Filosofía por la Universidad de Navarra -Pamplona, España-. Especialista en temas de filosofía moderna y antropología filosófica. Es miembro del CLAFEN (Círculo Latinoamericano de Fenomenologia) Actualmente prepara un libro sobre el tránsito del medievo a la modernidad en torno a la figura de Michel de Montaigne. Asimismo, es escritor y ha publicado recientemente un volumen de prosa poética titulado Las Moradas del abuelo. 
Contaba Nietzsche que cada vez que abría Los ensayos le crecía una pierna o un ala. Aquella publicación de Michel de Montaigne -divagatoria, miscelánea, fascinante- creó una brecha entre los géneros de la literatura filosófica, historiográfica y didáctica del siglo XVI y, con esa mezcla de frescor y consistencia de los clásicos precoces, inició el periplo de un estilo que atravesó airoso las modas y las ideas, y goza aún de espléndida salud.

Los ensayos (Les essais) es el libro detrás de los grandes libros de la tradición europea. Es la presencia, callada o revulsiva, que se halla implícita en los Ensayos de Bacon, el Discurso del método de Descartes, los Pensamientos de Pascal, el Ensayo sobre el entendimiento humano de Locke, las Confesiones de Rousseau y otros. Es también un alimento agradecido en el Nietzsche crítico de la modernidad y un claro en las tinieblas para un Horkheimer afligido al término de las dos grandes guerras del siglo anterior.

En una misiva a Louise Colet, Gustave Flaubert prorrumpe de este modo:

"Estoy releyendo a Montaigne. ¡Es singular hasta qué punto estoy lleno de ese individuo! [...] Tenemos los mismos gustos, las mismas opiniones, la misma manera de vivir, las mismas manías. Hay gente a la que admiro más que a él, pero no hay a quien evocaría más a gusto, y con quien charlaría mejor". ${ }^{2}$

Su biógrafo Jean Lacouture habla de él como "uno de los fundadores de la introspección" y "uno de los inventores de la sensibilidad y de la cultura occidental". ${ }^{3}$ Para Tzvetan Todorov, se trata del "primer verdadero humanista" en el sentido de aquel que piensa no que el humano es un ser formidable, sino uno indeterminado que tiene en la libertad la ocasión de su felicidad o su desdicha. ${ }^{4}$ Y en sus apuntes, Elias Canetti comenta: "Montaigne tiene esa actitud abierta hacia cualquier forma de vida humana que actualmente es universal y ha sido incluso elevada al rango de ciencia, pero él la tuvo en su época, una época fanáticamente convencida de su propia infalibilidad". ${ }^{5}$

¿Es decir demasiado? Narrando un avatar muy castellano, Cervantes talló un arquetipo universal. De este francés nacido en Gascogne (Gascuña) podría decirse que, ocupándose de asuntos personales, alentado por sus lecturas preferidas y sin deseos de escribir más que para sus amigos y parientes, ${ }^{6}$ acumu-

[2] “Será una coincidencia, o será porque a los dieciocho, durante todo un año, me atiborré de él, no leía más que a él? ¡Con frecuencia me deja atónito hallar en él el análisis más sutil de mis propios sentimientos!" (Cartas a Louise Colet, trad. Ignacio Malaxecheverría, Madrid, Ed. Siruela, 2003, p. 37)

[3] Montaigne a caballo, trad. Ida Vitale, México, Ed. Fondo de Cultura Económica, 2000, p. 11.

[4] Delicias y deberes. Una vida entre fronteras. (Entrevistas con Catherin Portevin), trad. Marcos Mayer, Buenos Aires, Ed. Fondo de Cultura Económica, 2003, p. 166-167.

[5] Apuntes I, trad. Juan José del Solar y Beatriz Galán, Barcelona, Ed. Debolsillo, 2008, p. 284-285.

[6] “¿Por qué ese latinista de nacimiento y de gusto eligió escribir en francés, lengua vulgar en su época? Él mismo esbozó una explicación: «Escribo mi libro para pocos hombres y para pocos años. Si hubiera tratado de asuntos de los que duran y persisten, habría sido preciso emplear en él un

THÉMATA. Revista de Filosofía, N 49 enero-junio (2014) pp.: 255-270 doi: 10.12795/themata.2014.i49.14 
ló un grueso de folios que con incomparable amenidad anticiparon algunas de las referencias que la mentalidad europea, incluso contemporánea, ha aprendido a asumir, apreciar e incluso a extrañar: la conciencia de la individualidad, la defensa de la libertad, la reflexividad unida a una gran vitalidad, la exhortación al diálogo, la celebración de la pluralidad, el valor formativo de los viajes y el sentido inclusivo de la tolerancia. A lo que se añade la originalidad con que Montaigne profesa una consonancia entre la mesura aristotélica y el fervor de los amantes del mundo, entre la ignorancia socrática y la avidez de lecturas y de encuentros, y entre la certeza de la propia finitud y la sincera confianza en el infinito.

Si, como dice Sándor Márai, ${ }^{7}$ describiendo el implacable proceso de estatalización y despersonalización de la sociedad húngara bajo la ocupación comunista, el mayor de los aportes del Viejo Continente a la historia es la delimitación del individuo y del sentimiento burgués -entendido no como una autocomplacencia social sino como el cultivo decidido de la propia alma-, no cabe, entonces, la menor duda de que Michel de Montaigne es un prócer de la cultura europea.

En la carta al lector de Los ensayos se lee: "yo mismo soy la materia de este libro", "me pinto a mí mismo". ¿Es acaso el inicio de un despliegue de vanidad de un millar y medio de páginas? ¿Es el preludio de un moroso ejercicio de ensimismamiento y evocación a la manera de Marcel Proust? Harold Bloom dice que uno termina de leer al gascón y todavía quiere saber más de él. El índice de Los Ensayos presenta estos encabezados: "sobre los caballos", "sobre la oratoria", "sobre la crueldad", "sobre el dormir", "sobre la guerra", "sobre Cicerón"... Extraña manera de tratar de uno mismo. Montaigne mismo confiesa: "no he hecho más a mi libro de lo que mi libro me ha hecho a mí". Versando sobre asuntos ajenos ha garabateado un retrato de sí mismo.

Pero en otro momento esclarece: "sea lo que sea, quiero serlo fuera del papel", pues "yo soy cualquier cosa antes que un escritor de libros. Mi cometido es dar forma a mi vida". Finalmente, el hombre desborda el texto, el yo se sitúa más allá de los actos y sus resultados. La vida, inaprehensible, aletea sobre el olor de la tinta y se escabulle para siempre.

lenguaje más firme»; dicho de otro modo, no escribió en latín por parecer más familiar, menos solemne, menos pretencioso". (Lacouture, Jean, Montaigne a caballo, p. 215)

[7] Los maestros de la sabiduría oriental "consideraban como objetivo final la disolución de la personalidad, el instante en que un individuo es capaz de traspasar los límites de su individualidad y se integra en el ritmo del universo. Para mí, para cualquier occidental, semejante visión del mundo suena a chino o hindú, porque si renuncio a mi personalidad -esa peculiar obsesión-, también renuncio al sentido de los lazos que me mantienen atado a la vida. [...] Ser burgués nunca ha sido para mí una categoría social; siempre he considerado que se trata de una vocación. La figura del burgués representa para mí el mejor fenómeno humano creado por la cultura occidental moderna: tras ser aniquilada la envejecida estructura social basada en la jerarquía feudal y haberse desmoronado en el mundo un orden social caduco, el burgués estableció un nuevo equilibrio. [...] "Ese ha sido el mayor regalo de Europa a la humanidad: el humanismo. ¿Qué es el humanismo? Una medida humana. La constatación de que el ser humano es el sentido último de la evolución, el desarrollo y el progreso.” (¡Tierra tierra!, trad. J. Xantus Szarvas, Barcelona, Ed. Salamandra, 2006, p. 109-110, 136 y 277)

THÉMATA. Revista de Filosofía, No 49 enero-junio (2014) pp.: 255-270 doi: 10.12795/themata.2014.i49.14 
Deseo proponer una aproximación hacia esa relación que tuvo Montaigne con la palabra como medio de configuración de una interioridad tan circunscrita como ávida y provista de una cierta pluralidad y, por ello, lugar de la conciencia de una finitud inseparable del mundo y al mismo tiempo indisoluble en él.

En sus Prosas apátridas, Julio Ramón Ribeyro concluye que la escritura no es algo que suceda con posterioridad al conocimiento, sino que más bien ocurre lo contrario. Cuando se dispone a evocar la Lima de su infancia desde el París de su adultez, empieza a descubrir, emocionado, que el barrio, el mar, el aire y todo en su memoria se llena y se precisa apenas empieza el tecleo de su máquina. Y los objetos se transfiguran tan pronto junta una frase con otra. "El acto de escribir -subraya- nos permite aprehender una realidad que hasta el momento se nos presentaba en forma incompleta, velada, fugitiva o caótica". 8

Las palabras aferran las cosas y proyectan sobre ellas una fuerza que, sin ser exhaustiva, es clarificadora. Designar es distinguir, delimitar, iluminar. El pensamiento se halla en un estado difuso y suspenso hasta que al fin lo recoge y transporta una fila de vocablos. Cuando Wittgenstein veía en el lenguaje un "vehículo del pensamiento", tenía en cuenta no una especie de vagón sobre el cual los conceptos se embalasen y remitiesen rumbo hacia lo público, sino más bien una ilación con la que fluía, inseparable, el mismo entendimiento. La verbalidad no es un signo del pensar, es el pensar en sí, entendido no como un producto final sino como actividad y creación.

Solo en el uso de un idioma particular -puesto que una lengua pura es irreal- nos apercibimos de lo que sabemos y de lo que no sabemos. Su utilidad no es, por tanto, extrínseca al hecho de la comprensión. Hablando discernimos. De manera que si, por una parte, la autoposesión y el diseño de la vida es una operación de la conciencia, por otra, ésta es indisolublemente una experiencia lingüística, como Gadamer sugiere. ${ }^{9}$ Somos cada uno, por dentro, un flujo de palabras.

Con bastante anterioridad a estas digresiones analíticas y hermenéuticas, Montaigne se propone escribir Los ensayos con la intención de comprender y comprenderse a sí mismo y hacerlo a través de la escritura. No parte de una sabiduría finiquitada que deseara exponer; más bien, alarga las manos y se pone a buscar. Y tocando las cosas encuentra sus propios contornos, su propia medida.

[8] Lima, Ed. Seix Barral, 2006, 55, pp. 49-50.

[9] "El lenguaje no es sólo una de las dotaciones de que está pertrechado el hombre tal como está en el mundo, sino que en él se basa y se representa el que los hombres simplemente tengan mundo. Para el hombre el mundo está ahí como mundo, en una forma bajo la cual no tiene existencia para ningún otro ser vivo puesto en él. Y esta existencia del mundo está constituida lingüísticamente. [...] La humanidad originaria del lenguaje significa, pues, al mismo tiempo la lingüisticidad originaria del estar-en-el-mundo del hombre". (Verdad y método I, trad. A. Agud A. y R. de Agapito. Salamanca, Ed. Sígueme, 2005, p. 531)

THÉMATA. Revista de Filosofía, N 49 enero-junio (2014) pp.: 255-270 doi: 10.12795/themata.2014.i49.14 
Así introduce sus espléndidos ensayos:

\begin{abstract}
"Lector, éste es un libro de buena fe. Te advierte desde el inicio que el único fin que me he propuesto con él es doméstico y privado. No he tenido consideración alguna ni por tu servicio ni por mi gloria. Mis fuerzas no alcanzan para semejante propósito. Lo he dedicado al interés particular de mis parientes y amigos, para que, una vez me hayan perdido cosas que les sucederá pronto-, puedan reencontrar algunos rasgos de mis costumbres e inclinaciones, y para que así alimenten, más entero y más vivo, el conocimiento que han tenido de mí. Si hubiese sido para buscar el favor del mundo, me habría adornado mejor, con bellezas postizas. Quiero que me vean en mi manera de ser simple, natural y común, sin estudio ni artificio. Porque me pinto a mí mismo. Mis defectos se leerán al natural, mis imperfecciones y mi forma genuina en la medida que la reverencia pública me lo ha permitido. De haber estado entre aquellas naciones que, según dicen, todavía viven bajo la dulce libertad de las primeras leyes de la naturaleza, te aseguro que me hubiera gustado muchísimo pintarme del todo entero y del todo desnudo. Así, lector, soy yo mismo la materia de mi libro; no es razonable que emplees tu tiempo en un asunto tan frívolo y tan vano. Adiós, pues. Desde Montaigne, a 12 de junio de 1580". ${ }^{10}$
\end{abstract}

Adorable forma de dirigirse al lector insospechado: amigo mío, perderás el tiempo pasando estas páginas; no tengo nada que ofrecerte, nada de lo que hay aquí es de tu incumbencia. Si buscas un saber, ve a pedirlo a otros. Yo solo hablo de mí mismo. ¿Qué puedes tú esperar de lo que tienes ahora ante tus ojos? Sé prudente, libra a tus manos de este peso y toma entero el tiempo que pensabas conmigo malgastar.

¿Puede haber estrategia más eficaz para ganar un cómplice? La prohibición o el esfuerzo disuasorio no hacen otra cosa que dar pábulo a la curiosidad. Decir que no se debe entrar es acercar una multitud hacia el umbral. Pero ocurre que el lector de la torre no soñaba con una masa de lectores. No sentía ningún ansia por los reembolsos de la fama. Su cometido en esta carta no es otro que la honradez y la precaución. Y, junto con ello, cubrirse las espaldas ante la inseguridad del volumen reunido.

Lo singular es que, poco después -como puede verificarse en el índice-, se pone a disertar sobre un elenco variopinto de temas -los carruajes, los parlamentos de las batallas, la muerte, los pulgares, la tristeza, unos versos de Virgilio, el canibalismo- y no sentimos nunca que esté ocupándose expresamente de sí mismo. Excepto, claro, como parte de esos desarrollos. Quizá es que sobre el mismo surco abierto por el extremo de su pluma se va percatando de lo que sabe y de lo que no, de lo que tiene y de lo que no tiene; y se va entendiendo a sí mismo de esa forma. ${ }^{11}$ Hablar de los asuntos que le salen al paso implica la ocasión de modular un enfoque y de mostrar lo que le gusta observar y el

[10] Los ensayos, trad. J. Bayod Brau, Barcelona, Ed. Acantilado, 2007, p. 5-6.

[11] En sus ensayos, "no es el valor de verdad como adecuación lo que cuenta, sino la simple exposición de un contenido de la consciencia. El texto no es reflejo del mundo, sino de sí mismo: los temas que elige, según la expresión de Regosin, no son sino lentes con las que Montaigne intenta enfocar el yo y comprenderlo". (Navarro, Jesús, Pensar sin certezas. Montaigne y el arte de conversar, Madrid, Ed. Fondo de Cultura Económica, 2007, p. 177)

THÉMATA. Revista de Filosofía, Nº 49 enero-junio (2014) pp.: 255-270

doi: 10.12795/themata.2014.i49.14 
modo de observarlo. Después de todo, escribiendo demarca el lugar desde donde mira y revela la propia fisonomía, como ésta se revela también en las fotos que tomamos al viajar y en las que no aparecemos y que, por eso justamente, nos delatan mejor al dejar a la vista nuestra atención a las cosas, el modo cómo nos aproximamos o alejamos de ellas, cómo las encuadramos, qué ponemos y qué excluimos del rectángulo, la hora y la luz que elegimos para abordarlas. Porque, en definitiva, también somos eso, una mirada que camina.

Es la misma esperanza que está detrás de la preferencia que tiene Montaigne por contar anécdotas de personajes de la historia, que Los ensayos dispensan a manos llenas. Él se rastrea a sí mismo en los actos de los otros, al revés de cómo hará Descartes que busca una ciencia válida para todos en el reducto de su sola conciencia: "en lugar de narrar los hechos de su propia vida -comenta Jesús Navarro-, dedica páginas y páginas a contarnos los de Catón, César, Atahualpa o algún campesino de su pueblo. [...] Al igual que las citas, las historias acerca de otros cumplen también una función oblicua, indirecta: no están ahí tanto para hablar de ellos como para hablar del propio sujeto que los cuenta". ${ }^{12}$

En su relato "El inmortal", Borges imagina la postración de una humanidad absuelta de su destino mortal.

"Adoctrinada por un ejercicio de siglos, la república de hombres inmortales había logrado la perfección de la tolerancia y casi del desdén. Sabía que en un plazo infinito le ocurren a todo hombre todas las cosas. [...] Encarados así, todos los actos son justos, pero también son indiferentes. No hay méritos morales o intelectuales. Homero compuso la Odisea; postulado un plazo infinito, con infinitas circunstancias y cambios, lo imposible es no componer, siquiera una vez, la Odisea. Nadie es alguien, un solo hombre inmortal es todos los hombres. Como Cornelio Agrippa, soy dios, soy héroe, soy filósofo, soy demonio y soy mundo, lo cual es una fatigosa manera de decir que no soy". ${ }^{13}$

Es la existencia de un tiempo acotado lo que nos apresura hacia la obra que decidirá nuestra figura. Aristóteles, hablando del origen de los hábitos, decía que la repetición de actos imprime cualidades en el sujeto agente. Si miento a menudo, me vuelvo mentiroso; si toco el piano con regularidad, seré mejor pianista... Pero en una duración sin contornos todo puede hacerse y todo puede acontecer, por eso nada apremia y el balanceo de la libertad se hace desidia. Cada momento se desmaya vacío de pasión. En lugar de las mil formas de la dicha, la inmortalidad mundana reportaría el sopor y la apatía. No una desfiguración sino la inexpresividad.

Con la convicción de que, como decía Pico de la Mirandola, venimos al mundo con una forma indeterminada y cada uno es su propio modelador, ${ }^{14}$ la

[12] Pensar sin certezas, p. 248.

[13] El aleph, Madrid, Ed. Alianza, 1972, p. 7 y ss.

[14] Cf. Discurso sobre la dignidad del hombre En Rodríguez Santidrián, P. (comp. y tr.) Humanis-

THÉMATA. Revista de Filosofía, Nº49 enero-junio (2014) pp.: 255-270 doi: 10.12795/themata.2014.i49.14 
acción por la que Montaigne quiere diseñarse a sí mismo no es otra que la construcción de su prosa. Las intervenciones públicas "dirán más sobre la fortuna que sobre mí. Dan testimonio de su papel, no del mío, salvo de manera conjetural e incierta". ${ }^{15}$ En las ocasiones comunes, nuestro obrar se enhebra con el de los demás y se confunde con variables sobre las que no tenemos dominio. Ese actuar entre los otros no nos representa fidedignamente. Si nos da a conocer, no nos agota. Sören Kierkegaard dirá mucho después que lo que peculiariza al humano es ese vivir para adentro, el ser una continua reflexión sobre sí mismo. Somos la conciencia que tenemos de nosotros. Y, como subraya Arnold Gehlen, el hombre es el único ser que necesita saber lo que es para serlo.

La redacción a que se aboca Michel de Montaigne no es, pues, el pasatiempo de quien deserta de unas funciones sociales o se jubila de una vida atareada. No es un empeño de recuperación, un descanso, un sustraerse a lo público -como le pasa a Machiavelli ante su biblioteca-, sino la ejecución de una tarea, la de edificarse a sí mismo. Inexcusable además. "Yo me exhibo entero. Esto es un skeletos [una anatomía] en el cual aparecen, en una sola visión, venas, músculos, tendones, cada pieza en su sitio. El acto de toser mostraba una parte; el acto de la palidez o del latido del corazón, otra, y de forma dudosa. No escribo mis acciones, me escribo yo, mi esencia". ${ }^{16}$

Hay libros que se escriben para vender o para impresionar a los lectores. Los ensayos, en cambio, se disfrutan porque tienen todo el rato esa tonalidad y ese candor de un trabajo nacido de una fuerza interior y no de la expectativa del aplauso. En las Cartas a un joven poeta, Rilke anotaba lo mismo, que había que escribir solo cuando fuera absolutamente necesario. ${ }^{17}$ Montaigne tomó asiento en su estudio motivado por la escritura propia antes que por la lectura ajena.

Y esta confección de su retrato fue, de paso, su respuesta al mandato socrático del autoconocimiento. ${ }^{18}$ "Y aunque nadie me lea, ¿he perdido acaso el

mo y Renacimiento, Madrid, Ed. Alianza, 1994, p. 121-122.

[15] Los ensayos, II, VI, p. 547.

[16] Los ensayos, II, VI, p. 547. Dice Peter Bürger: "su libro no sirve a un fin tercero y por ende extraño, es más bien un miembro de sus existencia." (El descubrimiento del sujeto moderno: Agustín, Montaigne, Descartes, Pascal, La Rochefoucauld, En Bürger, Christa y Bürger, Peter, La desaparición del sujeto. Una historia de la subjetividad de Montaigne a Blanchot, trad. A. González Ruiz, Madrid, Ed. Akal, 2001, p. 36)

[17] Cf. Cartas a un joven poeta, trad. José María Valverde, Madrid, Ed. Alianza, 1999, p. 24.

[18] "Los Ensayos aparecen en un ambiente especialmente proclive a la plasmación pictórica de los caracteres psicológicos -recuérdese la habilidad retratista de Jean y François Clouet, o los delicados esmaltes de Léonard Limousin-. De hecho, el propio Montaigne dejó constancia de la influencia que ejerció sobre él el floreciente género del autorretrato: «Vi un día en Bar-Le-Duc ofrceer al rey Francisco II para honrar la memoria de Renato, rey de Sicilia, un retrato que él había hecho de sí mismo. ¿Por qué no va a poder cada cual igualmente pintarse con la pluma, como él se pintaba con un lápiz?». [Ensayos II, 17]" (Navarro, Jesús, Pensar sin certezas, p. 166)

THÉMATA. Revista de Filosofía, Nº 49 enero-junio (2014) pp.: 255-270

doi: 10.12795/themata.2014.i49.14 
tiempo dedicándome tantas horas ociosas a pensamientos tan útiles y agradables? Al moldear en mí esta figura, he tenido que arreglarme y componerme tan a menudo para reproducirme, que el modelo ha cobrado firmeza y cierta medida forma él mismo. Al representarme para otros, me he representado en mí, con colores más nítidos que los que antes tenía. No he hecho más mi libro de lo que mi libro me ha hecho a mí". ${ }^{19} \mathrm{El}$ frescor de esta confianza es el entero arco de su encanto.

Hay que insistir en que, establecido el fin, el método escogido por Montaigne no fue demorarse ante su reflejo, inventariar lo vivido y describirse al detalle. Los ensayos no son un diario llevado con puntualidad; tampoco unas memorias que ordenen las peripecias de las que ha dimanado el rostro que tenemos, como en el caso de Rousseau, Casanova o Chateaubriand. ${ }^{20}$ La temática que ataca Montaigne es solo indirectamente alusiva a él.

Sobre la excepcionalidad del género incoado por Les essais, Navarro delibera que no estamos ni siquiera ante una autobiografía en el justo término: "la construcción de un personaje autobiográfico exigiría reducir la diversidad y variedad de lo ocurrido a una cierta coherencia, reinterpretar las mutaciones en clave evolutiva. Montaigne, aunque quiere plasmar sus alteraciones en el papel, renuncia abiertamente a establecer ese tipo de coherencia [...] Su técnica de redacción por añadidos, con escasas correcciones, permite al texto reflejar polifónicamente los diversos estados de su autor, sin que éstos queden unificados por el presente de la narración. Montaigne huye conscientemente de la rememoración autobiográfica porque ésta haría sucumbir su proyecto ante la tiranía del propio personaje: el autor a cada paso sentiría la tentación de forzar sus recuerdos para que dejen de ser episodios inconexos, y se integren en el devenir coherente de una única personalidad". ${ }^{21}$

Dicho brevemente, un corpus autobiográfico supondría una estructura, lo que en el caso de Montaigne aprisionaría su espíritu hasta sofocar su afán de buscarse y hacerse mientras escribe. Por el contrario, el ensayista deja emerger los múltiples perfiles que los turnos van extrayendo de él, como la manifestación de un semblante vivo y no embalsamado: "lo único que me propongo aquí es mostrarme a mí mismo, que seré tal vez distinto mañana si un nuevo aprendizaje me modifica". ${ }^{22}$ Cuánto parecido con esta prosa tiene el andar ocu-

[19] Los ensayos, II, XVIII, p. 1003.

[20] Para Bürger, Les essais "no es (como más tarde en Rousseau) un informe a posteriori con la intención de la autojustificación, sino el intento inconcluible de experimentar todo sobre sí”. (El descubrimiento del sujeto moderno: Agustín, Montaigne, Descartes, Pascal, La Rochefoucauld, p. 37)

[21] Pensar sin certezas, p. 168-169.

[22] Los ensayos, I, XXV, p. 186. Bellamente escribe Yourcenar sobre el Adriano de su novela: "Diversos personajes reinaban en mí sucesivamente, ninguno por mucho tiempo, pero el tirano caído recobraba rápidamente el poder. Albergaba así al oficial escrupuloso, fanático de disciplina, pero que compartía alegremente las privaciones de la guerra con sus hombres; al melancólico soñador

THÉMATA. Revista de Filosofía, N 49 enero-junio (2014) pp.: 255-270 doi: 10.12795/themata.2014.i49.14 
rrente, azaroso y libérrimo del Simon Tanner de una de las novelas de Robert Walser, e incluso la misma manera disforzada, llena de encantadores desvíos e improvisaciones, de la escritura de sus Microgramas.

Más que un retrato entendido como fijación, o un dique contra al tiempo, a la manera del Dorian Gray de Oscar Wilde, el francés cree más adecuado pergeñar algo parecido a una música, decurso en el cual la congelación de una sola nota desquiciaría el conjunto. Es decir, aceptar el movimiento natural que Da Vinci encontraba vacuo y deletéreo (y que le llevaba a preferir la pintura a la desdichada música que se desvanece tan pronto como suena). Por eso, el avance de Les essais es como el de una sucesión de eventualidades, cuya imprevisibilidad dice mucho más de lo que permitiría una estricta planificación. Lo que el ensayista no puede consentir, en todo caso, es traicionar la fragmentariedad, la volubilidad, la apertura, el discurrir del ser. Devenir sin dejar de ser y ser sin dejar de devenir, diría Ítalo Calvino a propósito del Ulises de Homero. De ahí que el género, el estilo y el lenguaje que emplea el francés calcen tan bien con su idea de la vida.

En Montaigne, dice Harold Bloom, el libro es el hombre y el hombre es el libro. De este crítico norteamericano tomo prestado el inigualable tributo al escritor de Los ensayos que hace Ralph Waldo Emerson en sus Hombres representativos de 1850 :

"La sinceridad y vitalidad del hombre se contagia a sus frases. No conozco ningún otro libro que parezca menos escrito. Es el lenguaje de la conversación trasladado a un libro. Cortad esas palabras, sangran; son vasculares y vivas. Nos proporcionan el mismo placer que cuando escuchamos las necesarias palabras de hombres que hablan de su trabajo, cuando cualquier circunstancia inusual proporciona una importancia momentánea al diálogo. Pues los herreros y los transportistas no se traban al hablar; son una lluvia de balas. Son los hombres de Cambridge los que se corrigen, y comienzan de nuevo a mitad de frase, y hacen juegos de palabras y son muy refinados, y se apartan de la cuestión que expresan. Montaigne habla con astucia, conoce el mundo, y los libros, y a él mismo, y siempre es positivo: nunca chilla, ni protesta, ni reza: no muestra debilidad, ni convulsión, ni superlativos: no desea salirse de su piel, ni hacer el payaso, ni aniquilar el tiempo o el espacio; pero es

de los dioses, al amante dispuesto a todo por un instante de vértigo, al joven teniente altanero que se retira a su tienda, estudia sus mapas a la luz de la lámpara, sin ocultar a los amigos su desprecio por la forma en que van las cosas, y al estadista futuro. Pero tampoco olvidemos al innoble adulador, que para no desagradar consentía en emborracharse en la mesa imperial, al jovenzuelo que opinaba sobre cualquier cosa con ridícula seguridad; al conversador frívolo, capaz de perder a un buen amigo por una frase ingeniosa; al soldado que cumplía con precisión maquinal sus bajas tareas de gladiador. Y mencionemos también a ese personaje vacante, sin nombre, sin lugar en la historia, pero tan yo como todos los otros, simple juguete de las cosas, ni más ni menos que un cuerpo, tendido en su lecho de campaña, distraído por un olor, ocupado por un aliento, vagamente atento a un eterno zumbido de abeja. Y sin embargo, poco a poco, un recién venido entraba en función: un hombre de teatro, un director de escena. Conocía el nombre de mis actores; arreglaba para ellos entradas y salidas plausibles; cortaba las réplicas inútiles; evitaba gradualmente los efectos vulgares. Aprendía a no abusar del monólogo. Poco a poco mis actos me iban formando". (Memorias de Adriano, trad. Julio Cortázar, Buenos Aires, Ed. Debolsillo, 2004, p. 57-58)

THÉMATA. Revista de Filosofía, No 49 enero-junio (2014) pp.: 255-270

doi: 10.12795/themata.2014.i49.14 
fuerte y recio; saborea cada momento del día; como el dolor, rara vez va a más o a menos; le gusta sentir terreno sólido, y piedras bajo los pies. En su escritura no hay entusiasmos, ni aspiración; satisfecho, respetuoso consigo mismo, se mantiene en un término medio. Con una sola excepción: su amor por Sócrates. Al hablar de él, por una vez se le sonroja la cara, y su estilo alcanza la pasión”. ${ }^{23}$

La dinámica de Los ensayos se resiste incluso a arrojar un estado de cuentas de los párrafos desgranados. Se limita a entregar el proceso, en cada uno de cuyos segmentos se refleja válidamente. Con tino argumenta Jesús Navarro que la obra podría muy bien llamarse autografía, pues para su autor la identidad personal reside más en la cadencia que en la sustancia, a sabiendas de que la vida no es un hecho biológico sino "el despliegue activo de una conciencia". ${ }^{24}$ Lo que hace su libro no es otra cosa que prolongar esta mudanza del espíritu. Montaigne no se plantea enunciar lo que él ya es, sino ser mientras escribe, mientras anota sobre unos pliegos que no son un lienzo cuyo modelo esté al frente, sino sencillamente la extensión de sí mismo.

"Mi oficio y mi arte es vivir", recuerda Montaigne. ${ }^{25}$ Escribir no lo es todo, es solo un camino. Pero, como diría Antonio Machado, el camino se hace al andar. Y dado que la vida es invención, cambiamos con las horas, no atravesamos intactos nuestras vicisitudes: "para enjuiciar a un hombre, hay que seguirle larga y atentamente la huella". ${ }^{26}$ La escritura recoge esta secuencia, en la que ni siquiera un punto o un rastro es todo el hombre. Este es el humanismo que Todorov premiaba en el francés: la enseñanza de que somos una permanente posibilidad, de que siempre hay más de lo que se ve y de lo que sucede.

"Los historiadores son lo que mejor se me da -desvela Montaigne-. Son, en efecto, amenos y fáciles; y, al mismo tiempo, el hombre en general, cuyo conocimiento busco, aparece en ellos más vivo y más entero que en ninguna otra parte, la diversidad y la verdad de sus condiciones internas en conjunto y en detalle, la variedad de los medios de su asociación y de los accidentes que le amenazan. Ahora bien, los que escriben vidas, dado que se ocupan más de las decisiones que de los resultados, más de lo que surge de dentro que de lo que ocurre fuera, me convienen más". ${ }^{27}$

[23] ¿Dónde se encuentra la sabiduría?, trad. Damián Alou, Madrid, Punto de Lectura, 2008, p. 160. Dice Zweig: "Escribe, pero no es un escritor. Escribir no es para él más que un entretenimiento. Buscar nuevas palabras le parece una «ambición infantil». Sus frases tienen que asemejarse al habla, a la conversación, tienen que figurar en el papel tan sencillas y simples como salen de la boca: serenas, nerviosas, cortas, no retorcidas ni afiladas. No deben ser pedantes ni "monacales», sino más bien «soldadescas»." (El legado de Europa, trad. Claudio Gancho, Barcelona, Ed. Acantilado, 2003, p. 52)

[24] Pensar sin certezas, pp. 210-212.

[25] Los ensayos, II, VI, p. 546.

[26] Los ensayos, I, XXV, pp. 484-485.

[27] "Por eso -remataba-, se mire como se mire, Plutarco es mi hombre". (Los ensayos, II, X, p. 598). Y en otra parte, se lee: "Suelo mirar también las epístolas ad Atticum [a Ático, de Cicerón] no ya porque contengan una amplísima enseñanza sobre la historia y los asuntos de su época, sino,

THÉMATA. Revista de Filosofía, N 49 enero-junio (2014) pp.: 255-270 doi: 10.12795/themata.2014.i49.14 
Paul Valéry proponía que uno es el cuerpo que creemos tener, otro el que los demás ven, y uno distinto el que examina el cirujano, el que la naturaleza ha prensado con tejidos y órganos. Según Sándor Marai, se puede hacer la misma distinción tripartita respecto del yo y su identidad. ${ }^{28}$ Una es la imagen que nos formamos de nosotros, con la que dialogamos a diario y que retocamos una y otra vez; otra la que se adhiere a la pupila ajena, la que en parte alimentamos, la que escapa de nosotros; y cosa muy distinta es lo que esencial y definitivamente somos, lo que subyace o corre bajo nuestros avatares y nuestros pensamientos.

Es evidente que la prosa de Montaigne no dará la medida exacta de este tercer yo. "Sea quien sea, quiero serlo fuera del papel", enfatiza. Sus hilvanaciones solo son diversos tratos con su ser profundo y, simultáneamente, puntadas con que urde el primer yo, el de la autoconciencia. La totalidad es esquiva, inabordable.

Al final, todo libro es una dualidad: mientras se hace, da fe del autor, fija lo que él es cada vez que alinea unas letras; cuando se lee, corre otra suerte y se distancia del ejecutor para formar un segundo yo, ese individuo público que siempre nos asombra, en el que ya no nos reconocemos y que en cierta forma tampoco nos concierne. La planicie de la página es una región de imprecisa frontera. Por más sin testigos que discurra el esmero de llenarla, como dirían Marai y Ribeyro, toda literatura es una impostación, un acto de representación. "Uno debe arreglarse, y uno debe ajustarse y componerse para mostrarse en público -aclara Montaigne-. Pues bien, yo me engalano sin descanso, ya que me describo sin descanso". ${ }^{29}$ Apariencia que es siempre una misteriosa proporción entre lo que muestra el actor y lo que otros ven, entre lo que él cree ser -en función de lo cual afina su gesticulación-y lo que interpreta y retiene la atención del espectador, que luego se va y ya no tiene más versión de aquél.

El caso es que el efecto de la escenificación de Los ensayos es de una inhabitual transparencia, al punto de que no cruje nunca la cáscara del fingimiento. Incluso, las contradicciones de su escritura consiguen el efecto de eludir lo acartonado. Es el logro que ha hecho de su lectura un caso de máxima proximidad entre las tres personas que uno puede ser.

mucho más, para descubrir sus inclinaciones privadas. Tengo, en efecto, singular curiosidad, como he dicho en otro sitio, por conocer el alma y los auténticos juicios de mis autores. Por la muestra de los escritos que exponen al teatro del mundo, debe enjuiciarse su capacidad, pero no su comportamiento ni su persona. [...] Preferiría saber a ciencia cierta qué charlaba [Bruto] en su tienda con algunos de sus amigos íntimos, en la vigilia de una batalla, a saber las palabras que pronunció al día siguiente ante su ejército; y lo que hacía en su gabinete y en su habitación, a lo que hacía en medio de la plaza y en el Senado". (Ibid., II, X, p. 596)

[28] ¡Tierra tierra!, p. 407.

[29] Los ensayos, II, VI, p. 545.

THÉMATA. Revista de Filosofía, No 49 enero-junio (2014) pp.: 255-270 doi: 10.12795/themata.2014.i49.14 
Hacen falta términos como los de Zweig para contarlo: "tomo los Ensayos en mis manos y desaparece en el espacio, en la penumbra, el papel impreso. Alguien respira, alguien vive conmigo, se me ha acercado un extraño y ha dejado de serlo para convertirse en alguien a quien siento cercano como un amigo. Cuatrocientos años se han desvanecido como el humo. No es el Seigneur de Montaigne, el gentilhomme de la Chambre de un rey de Francia desaparecido, ni es el señor del castillo de Périgord quien me habla; ha dejado la blanca gorguera plisada, el sombrero en punta y la espada, y ha retirado de su cuello la soberbia cadena de la Orden de Saint-Michel. No es el alcalde de Bordeaux quien ha venido a visitarme, ni es tampoco el escritor. Quien ha llegado es una amigo que me aconseja y que me habla de sí" ${ }^{30}$ El lector no se arrepiente de haber perseverado. El esfuerzo de las manos le pasa desapercibido. No se lee a Montaigne, se está un buen rato y tan a gusto con él.

Así, escribiendo sobre sí mismo, Montaigne descubre en su intimidad una historia. Para nada una línea recta sin torsiones, más bien una ondulación puntuada de ramificaciones. La página de san Agustín que Petrarca había abierto en lo alto del monte Ventoux, mencionaba la fascinación ante un interior dilatado por una galaxia de recuerdos, tan espléndido como cualquier paisaje frente al yo. Vestigios de momentos y personas de intensidades desiguales que hacen que el poeta del Cancionero pase de divisar la inmensidad natural a los pies de esa montaña a vislumbrar una vastedad más grandiosa dentro de su psique. Es entonces, dice Hans Blumenberg, cuando el término «mundo» experimenta una resignificación decisiva en la modernidad, al librarse "del sobrepeso de su orientación hacia la naturaleza" e incorporar la alusión "al universo del hombre", giro en el que es innegable la crucial contribución de Montaigne. ${ }^{31}$

El incremento de ejemplares por obra de la imprenta había posibilitado la formación de bibliotecas privadas, como la que Montaigne reunió en su torre con la doble herencia de su amado padre y su mejor amigo. La lectura silenciosa y retirada alentó a la conciencia a pasar de leer en voz alta a la articulación de una voz interior que, no necesitando grabar dentro de sí lo que ya poseía, se permitía ahora aventurarse y desplazarse a su aire. Una flotación de ideas, por último, se adensó aguardando el registro que le confiriese asiento. El aumento de las ocasiones de lectura personal, en suma, representó la sumersión en una individualidad que se exploraba y se ensanchaba a fuerza de palabras. Ahondando en mí mismo me multiplicaba, decía Fernando Pessoa. Montaigne es un pionero en la colonización de este "nuevo mundo" no avistado por telescopios ni alcanzado con carabelas. A partir de él, el discurso en primera persona no hará sino acrecentar su protagonismo en la modernidad.

[30] El legado de Europa, p. 18.

[31] La legibilidad del mundo, trad. Pedro Madrigal D., Barcelona, Ed. Paidós, 2000, p. 96.

THÉMATA. Revista de Filosofía, No49 enero-junio (2014) pp.: 255-270 doi: 10.12795/themata.2014.i49.14 
Lo espontáneo y casi disimulado de esta transición en Los ensayos es lo que torna más convincente y ejemplar el resultado. Dice Zweig que a Montaigne cada lectura que hace "lo incita a responder, a dar su propia opinión". De ahí su costumbre de "poner notas en los libros, subrayar y escribir al final la fecha en que leyó el libro o incluso la impresión que le produjo en aquella época". Sin embargo, "no se trataba de hacer una crítica ni de escribir libros, era un simple diálogo con el lápiz en la mano, y en principio nada estaba más lejos de él que consignar algo por escrito de manera continuada". Hasta que, llegado un momento, "para controlar sus propias ideas intenta consignar algunas por escrito. De ese modo la lectura ociosa se trueca en una actividad. No la ha buscado, se la ha encontrado". ${ }^{32}$

El siguiente paso en este proceso lo dará uno de sus más fervorosos lectores, nada menos que René Descartes que, aunque haría lo imposible por alejarse de la intemperie del escepticismo, llevará consigo adherencias y fraseos de sabor incuestionablemente montaigniano. En el primer capítulo de su Discurso del método dice: "me gustaría mostrar los caminos que he seguido, y representar así mi vida como en un cuadro". ${ }^{33}$ Etienne Gilson refiere que originalmente su autor había querido darle a este pequeño libro, detonante del racionalismo y la filosofía moderna, el título de Historia de mi pensamiento. ${ }^{34}$ De hecho, en él el también matemático Descartes une la fundamentación de su método al relato de sus decepciones escolares, de su etapa como soldado y de sus viajes por Europa, en un tono testimonial en primera persona, tan en el estilo de Los ensayos. Su enunciación es tanto la de una ciencia cuanto la de una confesión.

Por otra parte, quizá haya que achacar al imprevisible genio de Rousseau el que, al abrir sus propias Confesiones, tiempo después, diga casi ufano: "emprendo una obra de la que no hay ejemplo y que no tendrá imitadores". A no ser que entendamos como ostensible novedad el hecho de que el ginebrino se proponía algo que había escapado a las formas que guardaba el señor del castillo: mostrar una explícita referencia a sí mismo y no hacer más que contar la propia vida sin regatear pormenores.

"Quiero mostrar a mis semejantes un hombre en toda la verdad de la Naturaleza y ese hombre seré yo. Solo yo -retiñe Rousseau-. Conozco mis sentimientos y conozco a los hombres. No soy como ninguno de cuantos he visto, y me atrevo a creer que no soy como ninguno de cuantos existen. Si no soy mejor, a lo menos soy distinto de ellos. Si la Naturaleza ha obrado bien o mal rompiendo el molde en que me ha vaciado, solo podrá juzgarlo después de haberme leído. Que la trompeta del Juicio Final suene cuando quiera; yo, con este libro, me presentaré ante el Juez Supremo y le diré resueltamente: «He aquí lo que hice, lo que

[32] El legado de Europa, p. 47.

[33] Trad. Eduardo Bello, Ed. Tecnos, 1999, p. 6.

[34] Cf. La unidad de la experiencia filosófica, trad. Carlos Baliñas, Madrid, Ed. Rialp, 1998, p. 114-116.

THÉMATA. Revista de Filosofía, No 49 enero-junio (2014) pp.: 255-270

doi: 10.12795/themata.2014.i49.14 
pensé y lo que fui. [...] Me he mostrado como fui, despreciable y vil, o bueno, generoso y sublime cuando lo he sido. He descubierto mi alma tal como Tú la has visto, joh Ser Supremo! Reúne en torno mío la innumerable multitud de mis semejantes para que escuchen mis confesiones, lamenten mis flaquezas, se avergüencen de mis miserias. Que cada cual luego descubra su corazón a los pies de su trono con la misma sinceridad; y después que alguno se atreva a decir en tu presencia: Yo fui mejor que ese hombre»". ${ }^{35}$

Hablar frontalmente de uno mismo durante decenas de páginas requiere un desenfado y arriesga la tergiversación propia de la excesiva fijación. La observación afecta lo observado, sugerirá la física de Heisenberg siglos más tarde. Curiosamente, mientras Pascal culpa a Montaigne de demorarse en sí mismo dejándose llevar por el pecado del orgullo, Rousseau le imputa una "falta de sinceridad". ${ }^{36}$ Lo que sucede es que Montaigne no se escudriña para adularse y mucho menos lo hace fiándose de su propia falible mirada, sino acometiendo el temario dispar que su libro contiene. Entretenido entre las muchas cosas que lo atrapan, ve emerger su propio yo y solo después de acabado el texto escribe la carta al lector ya conocida. Rousseau se agota sacando una fotografía de sí mismo, yendo y viniendo por los laberintos de su pasado. El viajero perigordino, en cambio, dirige su lente hacia lo que lo circunda y hacia lo que su existencia andariega le obsequia a cada paso. Y en el desvío de esas tomas de gentes, autores y lugares que no son ni las inmediaciones de su castillo ni la textura de sus ropas, se le ve más íntegro y natural, a salvo de las adulteraciones de la sobreexposición. Sonriente, asimismo, porque de ninguna otra manera se siente Montaigne tan sí mismo como cuando amasa los tesoros inasibles del encuentro con las cosas. Por dentro, el yo es una pluralidad, seres a los que se quiere, momentos que se agradecen, finitud multiplicada.

[35] Confesiones, s/trad., México, Ed. CONACULTA Océano, 1998, p. 3.

[36] "No sé por qué capricho Rey me instaba respetuosamente hacía mucho tiempo a que escribiese las memorias de mi vida. Aunque hasta entonces no fuesen muy interesantes por los hechos, yo conocía que podían llegar a serlo por la franqueza que era capaz de usar; y resolví formar con ellas una obra única, por su veracidad sin ejemplo, a fin de que a lo menos una vez siquiera pudiese verse a un hombre tal como es interiormente. Siempre me había reído de la falta de sinceridad de Montaigne, quien, fingiendo confesar sus defectos, pone gran cuidado en no atribuirse sino aquellos que tienen carácter agradable; cuando yo, que siempre me he creído, y bien considerado, aun me creo el mejor de los hombres, estoy convencido de que no hay interior humano, por puro que sea, que no tenga algún vicio feo. [...] Por otra parte, como esto no era hacedero sin sacar a luz también el modo real de ser de otras personas, y por consiguiente no pudiendo esta obra aparecer sino después de mi muerte y la de muchos otros, esto me animó a hacer mis Confesiones, de que jamás habría de tener que avergonzarme delante de nadie. [...] Este proyecto de retiro absoluto, uno de los más sensatos que en mi vida haya formado, estaba impreso firmemente en mi espíritu, y ya me ocupaba en llevarlo a cabo, cuando el cielo, que me preparaba otra suerte, me arrojó en un nuevo torbellino." (Confesiones, p. 472)

THÉMATA. Revista de Filosofía, Nº49 enero-junio (2014) pp.: 255-270 doi: 10.12795/themata.2014.i49.14 


\section{Referencias bibliográficas:}

Agustín, San (2005), Confesiones. Trad. J. Cosgaya O.S.A. Madrid: Biblioteca de Autores Cristianos.

Aristóteles (1998). Metafísica. Trad. V. García Yebra. Madrid: Gredos.

Bloom, H. (2008) ¿Dónde se encuentra la sabiduría? Trad. Damián Alou. Madrid: Punto de Lectura.

Blumenberg, H. (2000) La legibilidad del mundo. Trad. Pedro Madrigal. Barcelona: Paidós.

Borges, J. L. (1972). El aleph. Madrid: Alianza.

Bürger, P. (2001). El descubrimiento del sujeto moderno: Agustín, Montaigne, Descartes, Pascal, La Rochefoucauld. En: C. Bürger y P. Bürger. La desaparición del sujeto. Una historia de la subjetividad de Montaigne a Blanchot. (p. 32-37) Trad. A. González Ruiz, Madrid: Ediciones Akal.

Canetti, E. (2008). Apuntes I. Trad. J. J. del Solar y B. Galán. Barcelona: Ed. Debolsillo.

Descartes, R. (1999). Discurso del método. Trad. E. Bello. Madrid: Tecnos.

Flaubert, G. (2003). Cartas a Louise Colet. Trad. Ignacio Malaxechevarría. Madrid: Siruela.

Fumaroli, M. (2011). La diplomacia del ingenio. De Montaigne a La Fontaine. Trad. C. Martínez. Barcelona: Acantilado.

Gadamer, H.-G. (2005), Verdad y método I. Trad. A. Agud. A. y R. de Agapito. Salamanca: Sígueme.

Grayling, A. C. (2007). Descartes. La vida de René Descartes y su lugar en su época. Trad. A. Lastra. Valencia: Pre-Textos.

Gilson, E. (1998) La unidad de la experiencia filosófica. Trad. Carlos Baliñas. Madrid: Rialp.

Lacouture, J. (2000). Montaigne a caballo. Trad. I. Vitale. México: FCE.

Márai, S. (2006). ¡Tierra tierra! Trad. J. Xantus Szarvas. Barcelona: Salamandra. Montaigne, M. de (2007). Los ensayos. Trad. J. Bayod Brau. Barcelona: Acantilado.

Montaigne, M. de (2010). Diario de viaje a Italia por Suiza y Alemania en 1580 y 1581, Trad. S. R. Santerbás. Madrid: Cátedra.

Montaigne, M. de (2014) Correspondencia, Trad. Constantino Román y 
Salamero. En Biblioteca Virtual Cervantes. Recuperado de http://www. cervantesvirtual.com/obra-visor/ensayos-de-montaigne--0/html/.

Pico della Mirandola, G. (1994) Discurso sobre la dignidad del hombre. En Rodíguez Santidrián, P. Humanismo y Renacimiento. Madrid: Alianza.

Plutarco (2006). Vidas paralelas, III Coriolano. Trad. A. Pérez Jiménez. Madrid: Gredos.

Navarro Reyes, J. (2005). La extrañeza de sí mismo. Identidad y alteridad en Michel de Montaigne. Sevilla: Fénix Editora.

Navarro Reyes, J. (2007). Pensar sin certezas. Montaigne y el arte de conversar. Madrid: FCE.

Ribeyro, J. R. (2003). La tentación del fracaso. Barcelona: Seix Barral.

Ribeyro, J. R. (2006). Prosas apátridas (completas). Lima: Seix Barral.

Rilke, R.-M. (1999) Cartas a un joven poeta. Trad. J. M. Valverde. Madrid: Alianza.

Rousseau, J. J. Confesiones (1998) México: CONACULTA.

Séneca (1982). Cartas a Lucilio. Trad. V. López S. Barcelona: Editorial Juventud.

Todorov, T. (2003). Delicias y deberes. Una vida entre fronteras. (Entrevistas con Catherin Portevin). Trad. M. Mayer. Buenos Aires: FCE.

Todorov, T. (2011). El jardín imperfecto. Luces y sombras del pensamiento humanista sobre la globalización. Trad. E. Folch González. Barcelona: Paidós. Yourcenar, M. (2004). Memorias de Adriano. Trad. Julio Cortázar. Buenos Aires: Debolsillo.

Zweig, S. (2003). El legado de Europa. Trad. Claudio Gancho. Barcelona: Acantilado. 